\title{
Glomalin-Related Soil Protein and Its Relationship with Organic Carbon and Nitrogen in Water-stable Aggregates in Abandoned Agricultural Lands
}

\author{
Zhao Xu ${ }^{1,2,3}$, Wang Cuili ${ }^{1}$, Zhao Jing ${ }^{5}$, Hou Beibei ${ }^{1}$, Li Yanrong ${ }^{1}$, Qiu Xiaoqing ${ }^{1}$, Song Panpan ${ }^{6}$, \\ Wang Junqiang ${ }^{1,4}$, \\ ${ }^{1}$ Soil Science Department, Gansu Academy of Agricultural Engineering and Technology, Wuwei, China \\ ${ }^{2}$ Institute of Technical Biology \& Agriculture Engineering, Hefei Institutes of Physical Science, Chinese Academy of Sciences, Hefei, China \\ ${ }^{3}$ University of Science and Technology of China, Hefei, China \\ ${ }^{4}$ Institute of Ecology, China West Normal University, Nanchong, China \\ ${ }^{5}$ No. 2 Middle School of Wenxian County, Longnan, China \\ ${ }^{6}$ College of Food Sciences \& Technology, Shanghai Ocean University, Shanghai, China
}

\author{
Email address: \\ zhaoxu512@.163.com (Wang Junqiang) \\ ${ }^{*}$ Corresponding author
}

\section{To cite this article:}

Zhao Xu, Wang Cuili, Zhao Jing, Hou Beibei, Li Yanrong, Qiu Xiaoqing, Song Panpan, Wang Junqiang. Glomalin-Related Soil Protein and Its Relationship with Organic Carbon and Nitrogen in Water-stable Aggregates in Abandoned Agricultural Lands. Journal of Energy and Natural Resources. Vol. 8, No. 1, 2019, pp. 37-44. doi: 10.11648/j.jenr.20190801.16

Received: February 27, 2019; Accepted: March 21, 2019; Published: April 28, 2019

\begin{abstract}
A large number of studies have shown that glomalin-related soil protein (GRSP) plays an important role in soil aggregate formation and soil carbon balance. However, to date, we lack understanding on the relationship between GRSP and water-stable aggregates (WSA) in abandoned agricultural lands of semi-arid region. We considered abandoned agricultural lands of different ages in Minqin Oasis as the research object. We discussed the changes of GRSP and the relationship between GRSP and WSA during land abandonment. The research results showed the following: the content of extractable glomalin-related soil protein (e-GRSP) and total glomalin-related soil protein (t-GRSP) is higher than that of traditional arable lands, and the content increases as the years of land abandonment increase. e-GRSP and t-GRSP contents are higher than the soil layer of 0-20 and 40$60 \mathrm{~cm}$ in terms of vertical section. The proportion ranges of e-GRSP and t-GRSP in soil total organic carbon (TOC) are $0.62 \%-$ $2.0 \%$ and $1.97 \%-8.1 \%$ respectively in the abandoned agricultural lands. e-GRSP and t-GRSP also exhibit significant quadratic correlation with TOC $(P<0.05)$. e-GRSP and t-GRSP have significant positive correlation with mean weight diameter $(P<0.05)$. Significant and extremely significant positive correlations are observed between the e-GRSP and t-GRSP and the WSA with particle sizes between $0.25-1$ and $>2 \mathrm{~mm}$ and the organic carbon (OC) and nitrogen $(\mathrm{N})$ existing in such sizes, respectively. In addition, significant and extremely significant negative correlation exist between the e-GRSP and t-GRSP and the clay and silt contents $(<0.053 \mathrm{~mm})$ and the OC and N in clay and silt. In general, land abandonment has raised the GRSP content. Moreover, the GRSP after land abandonment tends to promote large WSA formulation and organic matter enrichment in large aggregates. Organic matter accumulation in clay and silt was also inhibited. This phenomenon helps build a reasonable aggregate hierarchy and improve the stability of soil aggregates.
\end{abstract}

Keywords: Agricultural Land Abandonment, Organic Carbon, Nitrogen, Glomalin-Related Soil Protein, Water-Stable Aggregates

\section{Introduction}

Arbuscular mycorrhizal fungi (AM fungi) are important factors that affect soil physical and chemical properties. AM fungi not only improve soil structure and fix effective nutrients but also enhance the environmental conditions for 
microbial and enzyme activities. This phenomenon affects biological processes, such as soil respiration. Glomalin is a theoretically assumed heat-resistant glycoproteins secreted by the fungal mycelia of AM fungi and it possesses $37 \%$ carbon and 3\%-5\% nitrogen [1-2]. Glomalin in the soil is generally measured by glomalin-related soil protein (GRSP) [3]. Therefore, we can effectively predict the health status of soil by measuring the GRSP in soil [4].

As early as 1995, Pimentel et al. (1995) pointed out that almost $1 / 3$ of cultivated lands in the world suffered soil and water erosion in the past 40 years because of natural erosion [5]. This erosion would continue at a speed of $1.0 \times 10^{7} \mathrm{hm}^{2}$ per year. Previous studies showed that stable soil aggregates can reduce soil loss caused by natural erosion. Thus, the stability of soil aggregates is an important indicator of the quality of a soil ecosystem. Wright et al. (1998a) found that GRSP is an important cementing agent in the formation of soil aggregates [1]. These aggregates constitute the basic structural unit of soil. Such soil unit with stable structure can greatly improve the permeability of soil water, the soil stability, and the ability to prevent natural erosion. Meanwhile, its reasonable porous structure also provides necessary space and good air ventilation channels for plant growth. The soil aggregates are also important carriers of soil organic carbon (OC) and material base that maintains the stability of organic matter in soil [6]. The stable aggregates can provide effective protection for the organic matter existing in it. As a result, more OC can be captured. Therefore, we can indirectly evaluate the physical stability of soil organic matter in this area by studying the trend of GRSP content changes and its relationship with organic matter in aggregates.

Several studies have been carried out on soil organic matter and GRSP considering formation and stability of soil aggregates [4, 6-7]. To date, however, we lack sufficient understanding about the vertical distribution of GRSP in the soil of abandoned agricultural lands of semi-arid desert region or the relationship between GRSP and water-stable aggregates (WSA). Therefore, the research aims to explore the influence of GRSP on soil organic matter pool and its functions in maintaining water stability of soil aggregates by studying GRSP changes during land abandonment and the relationship between GRSP and OC and N in WSA.

\section{Methods}

\subsection{Description of Sites and Sampling}

\subsubsection{Study Sites}

Minqin Oasis $\left(38^{\circ} 03^{\prime}-39^{\circ} 27^{\prime} \mathrm{N}, \quad 101^{\circ} 49^{\prime}-104^{\circ} 12^{\prime} \mathrm{E}\right)$ is located in the Shiyang River basin of Gansu Province in Northwest China. Minqin Oasis has a land area of 159.107 $\mathrm{km}^{2}$ and a population of approximately 306,900 . The elevation of the region ranges from $1,295 \mathrm{~m}$ to $1,460 \mathrm{~m}$. The relief is generally downward from southwest to northeast. The oasis is surrounded by the Badain Jaran Desert in the west and north and the Tengger Desert in the east. The area is characterized by an arid continental climate with an annual mean temperature of $7.8^{\circ} \mathrm{C}$ (average maximum of $23.2^{\circ} \mathrm{C}$ in July and average minimum of $-9.6^{\circ} \mathrm{C}$ in January), low and irregular rainfall, high evaporation, and prolonged drought periods. The mean annual precipitation is $110 \mathrm{~mm}$ with uneven distribution, but the annual potential evaporation exceeds 2,664 $\mathrm{mm}$ [8], because of the arid climate and scarce water resources in the area. The ecosystem of Minqin Oasis is extremely fragile. Minqin Oasis is also one of the most severely desertificated regions in China.

\subsubsection{Soil Sampling}

The agricultural lands were selected and the soil sampling methods were performed as described by Wang et.al [9]. Briefly, we selected 0 (control, cultivated land), 3, 12, 20, 30, and 40 years abandoned agricultural lands in the northeastern part of Minqin Oasis within a radius of $6 \mathrm{~km}$. These lands all have well-known land-use history and current management practices and experienced similar tillage and cultivation practices in the years. Moreover, the lands were arable for many decades. All the study sites exhibited the same topography and soil type (anthropogenic alluvial soil). In April 2012, sampling locations with three replications were selected within a distance of $1.0-1.5 \mathrm{~km}$ to avoid pseudoreplication. Five $(10 \mathrm{~m} \times 10 \mathrm{~m})$ soil sampling subplots were randomly established at each sampling locations ( 6 age classes $\times 3$ replications $=18$ sampling locations) with a minimum separation distance of $100 \mathrm{~m}$. Fifteen soil cores (by a sample probe) were randomly collected in each subplot at depths of $0-20,20-40$, and $40-60 \mathrm{~cm}$. Visible roots, coarse plant debris, and stone fragments were removed manually at the time of sampling. Soil samples were crushed and divided into two portions. One portion was passed through a $4.75 \mathrm{~mm}$ sieve for aggregate-size fractionation and GRSP determination. Then, the next one was passed through a $2 \mathrm{~mm}$ sieve to determine the entire $\mathrm{OC}$, total $\mathrm{N}$ contents, and other physicochemical properties of soils.

\subsection{Laboratory Analyses}

\subsubsection{Water-Stable Aggregate (WSA) Fraction}

WSA were fractionated using wet-sieving method [10-11]. Briefly, $100 \mathrm{~g}$ soil samples were passed through four sieves successively with decreasing mesh diameter $(2,1,0.25$, and $0.053 \mathrm{~mm}$ ) and gently suspended in water for $5 \mathrm{~min}$ at room temperature. Then, aggregates were separated by moving the sieves up and down $(3 \mathrm{~cm}) 50$ times for $2 \mathrm{~min}$. Soil aggregates were separated into five size classes: $>2,1-2,0.25-1,0.053-$ 0.25 , and $<0.053 \mathrm{~mm}$. Macroaggregates were defined as the $>2,1-2$, and $0.25-1 \mathrm{~mm}$ fractions, and microaggregates were defined as the $0.053-0.25 \mathrm{~mm}$ size fraction [12]. WSA fractions $<0.053 \mathrm{~mm}$ were defined as silt plus clay size particles [13]. After the 2 min cycle, WSA retained on sieves were gently backwashed off the sieve into pre-weighed aluminum pan, oven dried at $60^{\circ} \mathrm{C}$ for $48 \mathrm{~h}$, weighed, and prepared for mean weight diameter (MWD) calculation and soil $\mathrm{OC}$ and $\mathrm{N}$ analyses. Floating organic material $(>2 \mathrm{~mm})$ was decanted and discarded because this large organic material is, by definition, not considered soil organic matter. 
MWD of each sample was calculated by using Eq. 1 [14-15].

$$
\mathrm{MWD}=\sum_{i=1}^{\mathrm{n}} \boldsymbol{X}_{i} \boldsymbol{W}_{j}
$$

Where $X_{i}$ is the mean diameter of each size fraction, and $W_{j}$ is the proportion of total sample weight in the corresponding size fraction.

\subsubsection{GRSP Determination}

The extractable glomalin-related soil protein (e-GRSP) and total glomalin-related soil protein (t-GRSP) were extracted using the methods of Wright et al. (1996c) and Xie et al. (2011) [16-17]. GRSP concentration measurement was performed using Coomassie brilliant blue method to determine the protein. In other words, bovine serum albumin was used as the standard substance to draw the standard curve. Meanwhile, the absorbance of the sample to be tested was measured by ultraviolet spectrophotometer. Concentration - absorbance equation can be used to determine the concentration of t-GRSP and e-GRSP. We can also identify the content of t-GRSP and e-GRSP in unit quality of soil by combining the volume of leach liquor and the soil quality during leaching and extracting.

\subsubsection{Sample Analysis}

Soils were sieved through a $2 \mathrm{~mm}$ mesh and analyzed for $\mathrm{pH}$, electrical conductivity (EC), and soil particle composition. Additional subsamples were passed through a $0.25 \mathrm{~mm}$ sieve and analyzed for soil total organic carbon (TOC) and $\mathrm{N}$ content. In the sample plots, three additional soil samples were collected using core method to determine bulk density at depths of $0-20,20-40$, and $40-60 \mathrm{~cm}$. TOC and N content of the entire soil profile and size fraction of WSA were determined by $\mathrm{K}_{2} \mathrm{Cr}_{2} \mathrm{O}_{7}-\mathrm{H}_{2} \mathrm{SO}_{4}$ digestion method and Kjeldahl procedure [18], respectively. Soil $\mathrm{pH}$ values were determined with a glass electrode using a 1:1 soil-to-water ratio. EC was measured with an EC meter using a 1:5 soil-to-water ratio. Soil particle composition was determined by hydrometer method [19]. Measurement of root biomass (RB) is detailed in the work of DuPont et al. (2010) [20].

\subsection{Statistical Analysis}

Pearson correlation test was used to test the contents of e-grsp and t-grsp in different soil depths. Two-way ANOVA was used to analyze the effects of time of land abandonment, soil depth, and their interactions on soil e-GRSP and t-GRSP contents. All analyses were conducted using SPSS 19.0 software for Windows (SPSS Inc., IL, USA). The results were presented as mean $\pm \mathrm{SD}, n=3$. SigmaPlot 10.0 software was also used for graphics.

\section{Result}

\subsection{Distributions of e-GRSP and t-GRSP in Vertical Section in Abandoned Agricultural Lands}

The e-GRSP content at a depth of $0-20 \mathrm{~cm}$ is between 57.1 and $73.7 \mu \mathrm{g} / \mathrm{g}$ in the abandoned agricultural lands. This value accounts for $1.1 \%-1.9 \%$ of soil TOC. In addition, t-GRSP content is between 92.2 and $275.3 \mu \mathrm{g} / \mathrm{g}$, accounting for $3.4 \%$ $7.3 \%$ of TOC. These values are significantly higher than those of traditional arable lands after 12 years of land abandonment. The contents of e-GRSP and t-GRSP are between 64.7 and $122.6 \mu \mathrm{g} / \mathrm{g}$ and 233.8 and $491.9 \mu \mathrm{g} / \mathrm{g}$, respectively, at a depth of $20-40 \mathrm{~cm}$. These values are significantly higher than the values at the depths of $0-20$ and $40-60 \mathrm{~cm}$ (Figure 1). Moreover, their proportions in TOC are between $1.6 \%-2.0 \%$ and $5.8 \%-8.1 \%$, respectively. The values are significantly higher than those of traditional cultivated lands three years after land abandonment. The changes of e-GRSP and t-GRSP at a depth of 40-60 $\mathrm{cm}$ are the smallest among the three soil layers. The difference is not significant before 30 years of land abandonment, whereas the content significantly increased 30 years after land abandonment. The average proportions of e-GRSP and t-GRSP 3 in TOC are $0.62 \%$ and $1.97 \%$, respectively (Figure 1). In general, e-GRSP and t-GRSP exhibit an increasing tendency as the years of land abandonment are extended. The interaction between years of land abandonment and soil layers have imposed extremely significant influence on t-GRSP $(P<0.001)$ and significant influence on e-GRSP $(P<0.05)$, respectively (Table 1$)$.

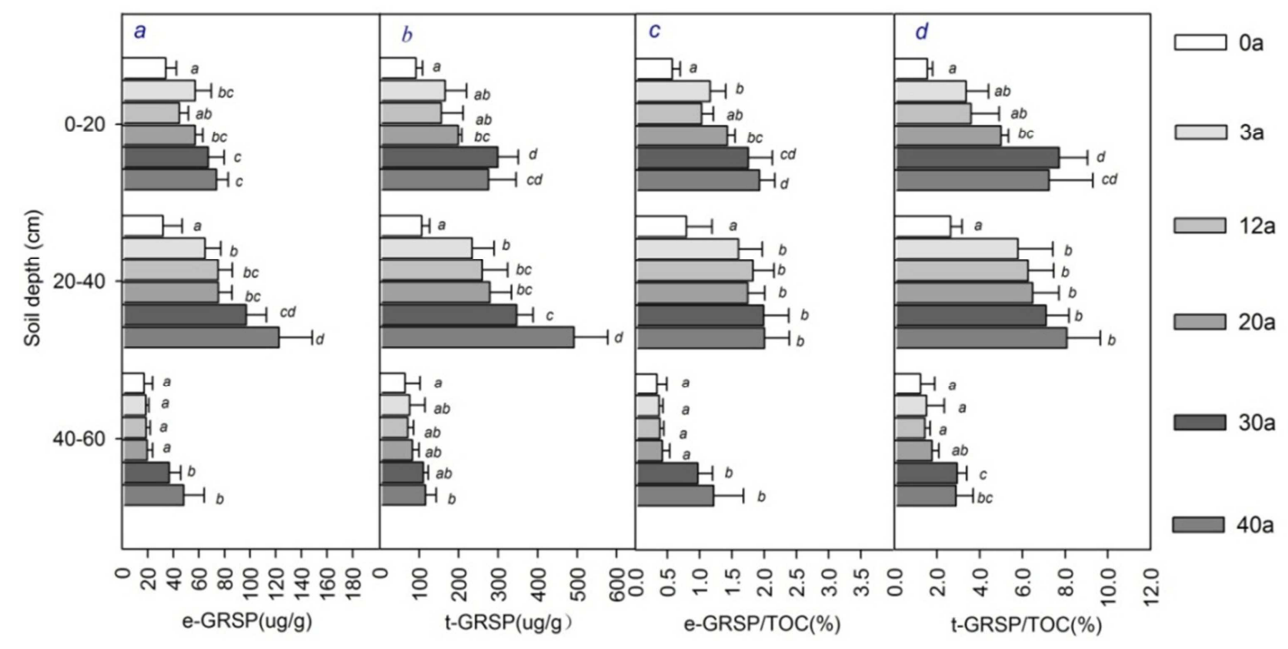

Figure 1. Vertical distribution of e-GRSP and t-GRSP on abandoned farmlands. 
Table 1. Two-way ANOVA for soil GRSP.

\begin{tabular}{lllllll}
\hline \multirow{2}{*}{ Index } & \multicolumn{2}{l}{ Abandonment time(A) } & Soil depth(B) & \multicolumn{1}{l}{ A $\times$ B } \\
\cline { 2 - 7 } & $\boldsymbol{F}$ & $\boldsymbol{P}$ & $\boldsymbol{F}$ & $\boldsymbol{P}$ & $\boldsymbol{F}$ & $*$ \\
\hline e-GRSP & 21.547 & $* * *$ & 23.007 & $* *$ & 2.233 & $*$ \\
t-GRSP & 23.007 & $* * *$ & 85.451 & $* * *$ & 4.729 & $* * *$ \\
\hline
\end{tabular}

Note: *** means significant difference at $P<0.001$ level. * means significant difference at $P<0.05$ level.

\subsection{Relationship Between GRSP and WSA in Abandoned Agricultural Lands}

Figure 2 shows significant and extremely significant positive correlations between e-GRSP and t-GRSP and large WSA with particle sizes of $0.25-1,1-2$, and $>2 \mathrm{~mm}$. In addition, significant and extremely significant relationships exist between e-GRSP and t-GRSP and clay and silt content $(<0.053 \mathrm{~mm}$ ), respectively (Figures. $2: \mathrm{i}, \mathrm{j})$. However, e-GRSP

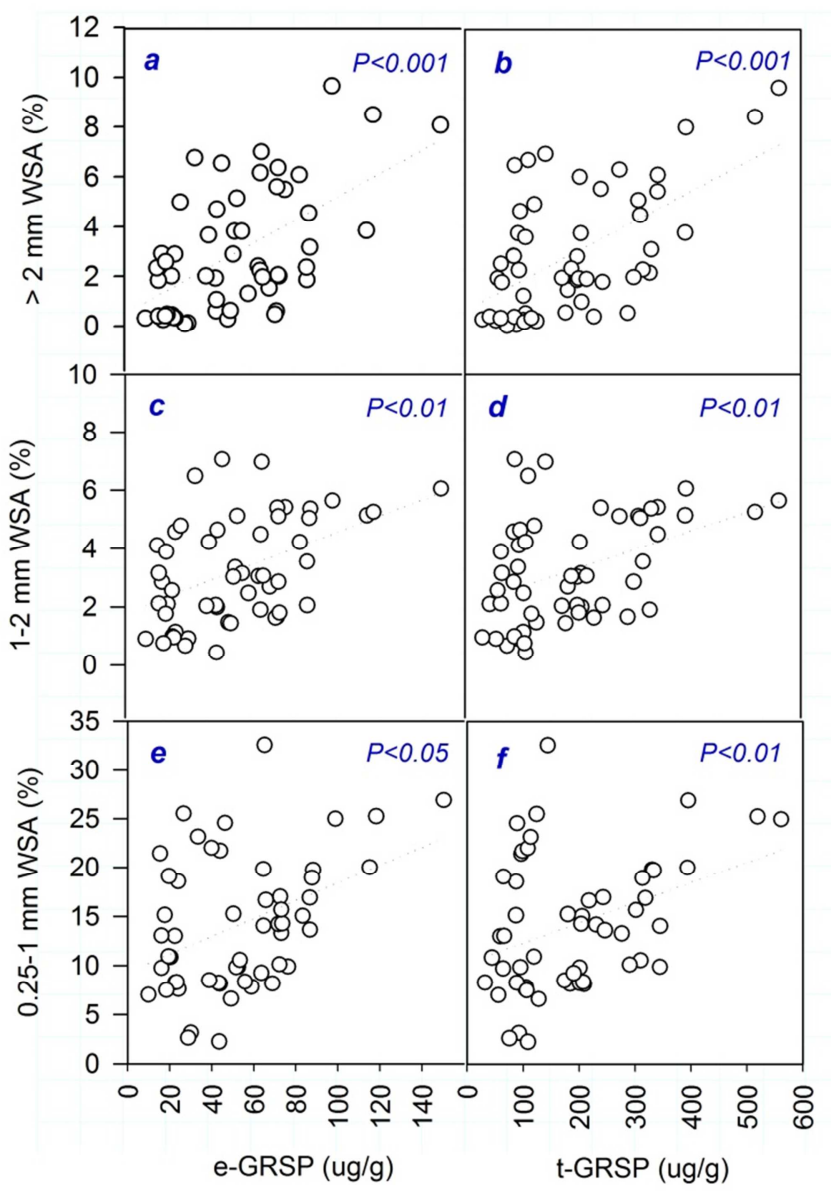

and t-GRSP do not exhibit significant relationship with micro WSA with particle sizes between 0.053 and $0.25 \mathrm{~mm}$. The correlation between t-GRSP and WSA is higher than that between e-GRSP and WSA. Significant linear correlation is observed between MWD and e-GRSP (k: $P<0.05$ ). Moreover, extremely significant linear correlation is observed between MWD and t-GRSP (1: $P<0.01)$.

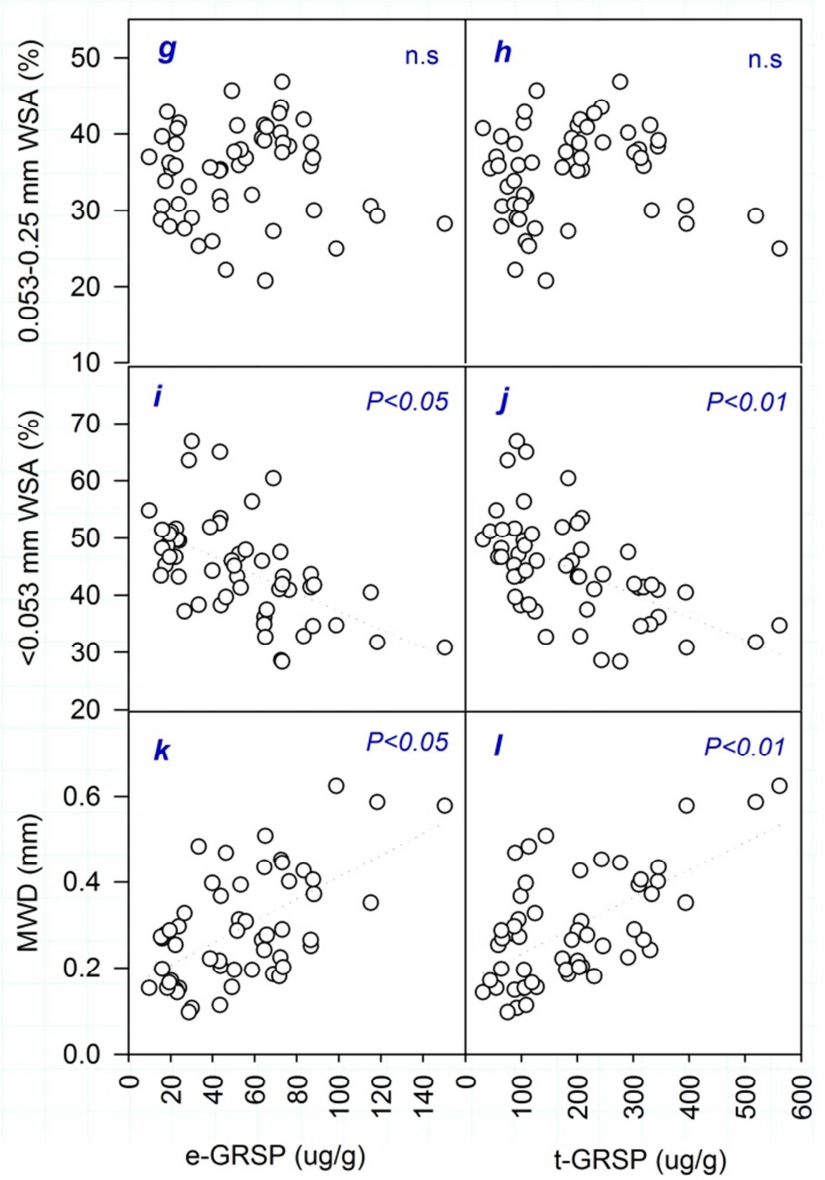

Figure 2. Relationship of e-GRSP and t-GRSP with WSA distribution and its stability.

\subsection{Relationship Between GRSP and $O C$ and $N$ in Agricultural Lands Left Uncultivated}

The correlation analysis shows significant linear correlations between e-GRSP and t-GRSP and OC and $\mathrm{N}$ contents for WSA with particle sizes of $>2$ and $0.25-1 \mathrm{~mm}$ (Figures. 3a, b, e, and f; $P<0.01$ ). The contents of $\mathrm{OC}$ and $\mathrm{N}$ do not exhibit significant correlation with e-GRSP and t-GRSP statistically in WSA with other particle sizes. Significant negative correlations exist between e-GRSP and t-GRSP and
OC content in clay and silt $(<0.053 \mathrm{~mm})$ (i; $P<0.05)$. In addition, extremely significant negative correlation is observed between e-GRSP and t-GRSP and $\mathrm{N}$ content in clay and silt $(<0.053 \mathrm{~mm})(\mathrm{j} ; P<0.05)$. TOC first decreases and then increases as the contents of e-GRSP and t-GRSP increase in the study site. Both of them exhibit significant quadratic correlation $(\mathrm{k}, 1 ; P<0.05)$. However, no significant correlations are observed between TN and e-GRSP and t-GRSP. 


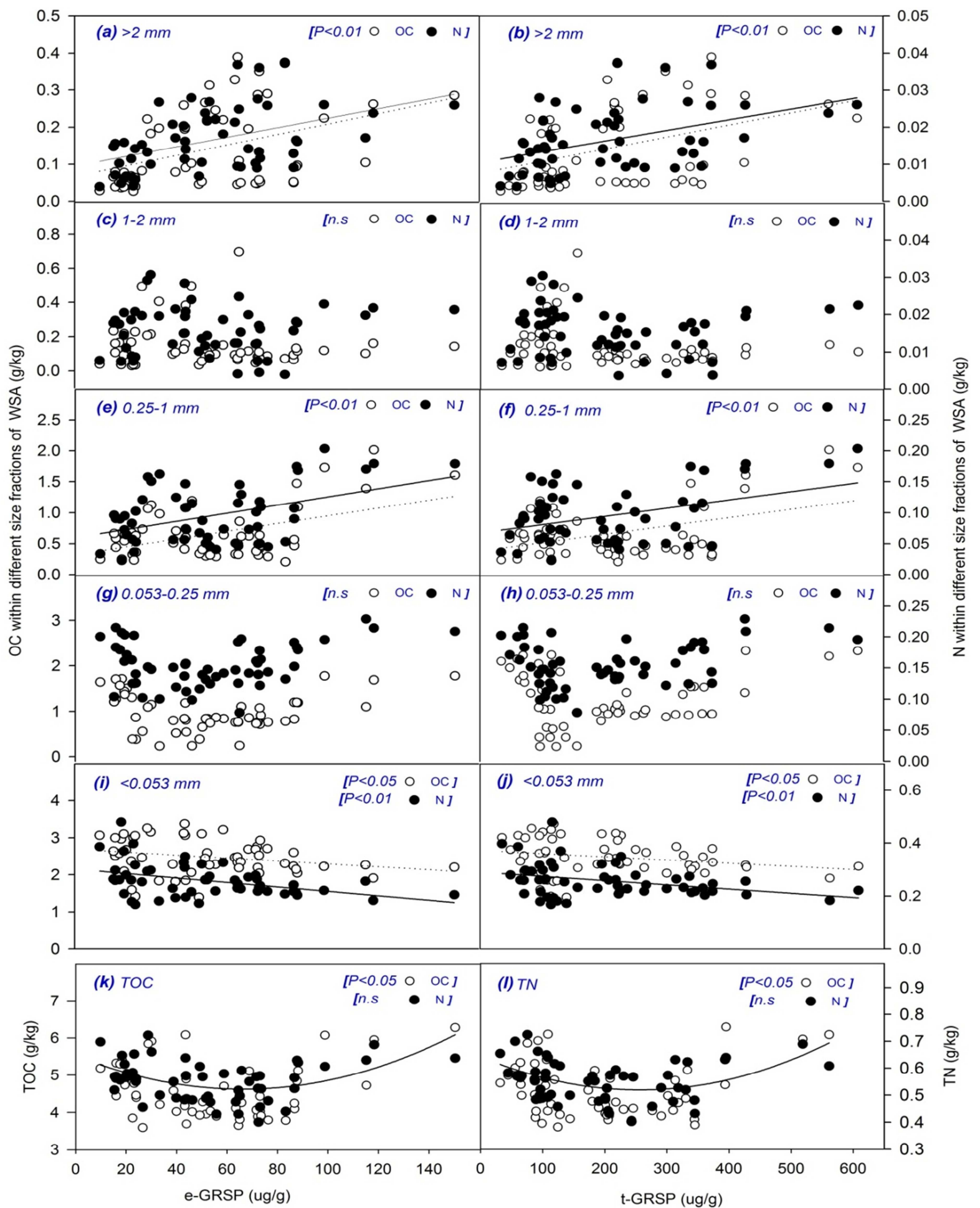

Figure 3. Relationship of e-GRSP and t-GRSP with OC and N within different fractions of WSA, TOC, and TN.

n.s. means no significance $(n=54)$. Black line indicates the correlation of soil OC content in different WSA and e-GRSP and t-GRSP. Dotted line indicates the correlation of soil $\mathrm{N}$ content in different WSA and e-GRSP and t-GRSP.

Table 2. Analysis of e-GRSP and t-GRSP with physicochemical properties in soil by a function of the time after abandonment of arable land.

\begin{tabular}{|c|c|c|c|c|c|c|c|c|c|c|c|c|c|c|}
\hline & BD & RB & Sand & Clay & Silt & pH & EC & $\mathrm{CaS}$ & $\mathrm{C} / \mathrm{N}$ & $\mathrm{Na}^{+}$ & $\mathrm{Ca}^{2^{2+}}$ & $\mathbf{M g}^{2+}$ & aP & aK \\
\hline & $379 * *$ & 0.240 & 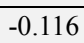 & & $0283 *$ & $0.583 * *$ & 0100 & 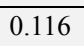 & & 0190 & $0313 *$ & -0.186 & 0.054 & 0.133 \\
\hline t-GRSP & $-0.422 * *$ & $0.273 *$ & -0.172 & -0.056 & $0.291 *$ & $0.630^{* *}$ & 0.231 & 0.172 & 0.180 & 0.243 & $0.330 *$ & -0.035 & 0.026 & 0.186 \\
\hline
\end{tabular}

Note: $n$ (samples) $=54$; * indicates significance at 0.05 level and ** indicates significance at 0.01 level. EC, electrical conductivity; BD, bulk density; RB, root biomass; $\mathrm{CaS}$, clay and silt content; aP, available phosphorus; and aK, available potassium. 


\section{Discussion}

\subsection{Contents and Distribution Laws of GRSP in Abandoned Agricultural Lands}

Previous studies showed that glomalin content in soil varies greatly among different ecosystems, ranging from $2.0 \mathrm{mg} / \mathrm{g}$ to $14.8 \mathrm{mg} / \mathrm{g}[16,21-22]$. The research shows that the content of e-GRSP is between 57.1 and $73.7 \mu \mathrm{g} / \mathrm{g}$ at a depth of $0-20 \mathrm{~cm}$, which accounted for $1.1 \%-1.9 \%$ of TOC. The content of t-GRSP is between 92.2 and $275.3 \mu \mathrm{g} / \mathrm{g}$, accounting for $3.4 \%$ $7.3 \%$ of TOC (Table 1). e-GRSP and t-GRSP contents are significantly lower than values in the previous research results The possible reason is that the dominant species of phytocoenosium prevailed, and the vegetation coverage is less after the agricultural lands are abandoned [23]. This phenomenon prevents the AM fungi from growing and limits the increases of GRSP contents in soil to a certain degree. GRSP relies on plants that co-exist with fungi to increase the secretion quantity in the soil and regulate the soil functions. Moreover, the contribution that the external hyphae of AM fungi provide to the OC relies on the secretion of hypha [1]. In addition, e-GRSP and t-GRSP first increase and then decrease with increasing depth in the soil layers. This result is quite similar to the research results of Talbot et al. (2008) [24], whereas it is different from the research results of Zhong et al. (2015) [25]. Significant positive correlation is observed between RB and t-GRSP (Table $2 ; P<0.05$ ). Therefore, the differences of GRSP contents in different depths of soil layers affect the different distribution densities of plant root systems in different soil layers. Besides, this finding might be relevant to the different $\mathrm{CO}_{2}$ concentrations in air of different soil layers [26]. The results showed an extremely significant negative correlation between GRSP and bulk density (Table 2; $P<0.01)$. GRSP content in traditional arable lands ( 0 year) was low, which might be relevant to the increase of soil bulk density [9]. The increase of soil bulk density restricts the chemical penetration ability of plant root systems and AM fungi hyphae. This phenomenon further constrains the GRSP secretion of AM fungi in the soil.

\subsection{Relationship Between GRSP and TOC and TN in the Soil of Abandoned Agricultural Lands}

The relationship between GRSP and soil OC and nitrogen is reported in many studies [3, 23, 27]. Numerous studies have shown significant linear positive correlation between GRSP and OC and nitrogen in certain soil layer or entire soil section. However, the relationship between soil GRSP and soil OC and nitrogen in abandoned agricultural lands of semi-arid region is seldom mentioned. We studied the correlations between GRSP and soil OC and nitrogen at different depths of soil layers. Moreover, the results show that the contents of e-GRSP and t-GRSP exhibit a tendency that they first decrease and then increase as the contents of TOC and TN increase, and they have significant quadratic relationship (Figure 3). This finding is quite different from the conclusion of Wright et al. (1996a) [28], that is, liner correlations. The relationship between soil GRSP and OC also reflects the controversy in academic circles in recent years, that is, the contribution that AM fungi provides to the soil OC. The traditional viewpoint about carbon cycle states that AM fungi are the effective carriers of plant carbon source and aid in transporting carbon through soil. However, increasing studies have shown that AM fungi can accelerate the decomposition of surface litter, leading to short-term loss of OC [29]. In addition, AM fungi as a decomposer of soil OC will directly lead to its loss [24-25]. This phenomenon will accelerate global warming [30]. Thus, loss of soil OC becomes rapid [26]. In general, OC can promote mycorrhizal development at varying degrees in the soil with high organic matter; however, such promotion is confined within a certain range [31]. Therefore, OC can also promote mycorrhizal development in soil containing relatively low organic matter (e.g., the soil in the study site). However, such promotion is limited. Therefore, the relationship between GRSP and OC is not a significant linear correlation and needs further and in-depth studies.

\subsection{Relationship Between GRSP and WSA in Abandoned Agricultural Lands}

The results of this study showed that both e-GRSP and t-GRSP exhibit significant positive correlations with MWD (Figures. 2k, 1). Therefore, GRSP can improve the stability of soil aggregates. This finding is identical with most previous studies [9, 24]. However, the correlation between t-GRSP and MWD is higher than that between e-GRSP and MWD. The reason might be that the stability of e-GRSP is poorer than that of t-GRSP; thus, e-GRSP is transformable to the difficultly extractable GRSP [7]. This finding can explain the different contributions that e-GRSP and t-GRSP provide to the stability of aggregates [33].

Existing studies show that the effect of GRSP relies on particle sizes of aggregates. The studies of $\mathrm{Wu}$ et al. (2012) show that GRSP can significantly promote the formation of aggregates with particle sizes $<1 \mathrm{~mm}$ [4]. In addition, GRSP can significantly inhibit the formation of aggregates with particle sizes between 1 and $2 \mathrm{~mm}$. Rillig et al. (2003) have found that e-GRSP and t-GRSP exhibit negative correlations with soil WSA with particle sizes between 1 and $2 \mathrm{~mm}$ in soil of Stipa tenacissima [7]. Research of Feng et al. (2001) shows that GRSP can significantly promote the formation of large aggregates with particle sizes between 1 and $2 \mathrm{~mm}$ [34]. The results of this study showed that e-GRSP and t-GRSP exhibit significant positive correlation with WSA with particle sizes $>0.25 \mathrm{~mm}$ (Figure 2). Thus, e-GRSP and t-GRSP can significantly promote the formation of large WSA with particle sizes $>0.25 \mathrm{~mm}$. The increase of WSA content with large particle sizes can help improve soil MWD [35]. This effect further improves the stability of aggregates. Besides relying on GRSP, the stability of aggregates also relies on many factors, such as root system, hypha, root secretion, and soil OC [32]. 


\subsection{Relationship Between GRSP and $O C$ and $N$ in the WSA of Abandoned Agricultural Lands}

Research has shown that, as a carbon source of soil, the sequestration effect of AM fungi on soil is formed during stabilizing soil aggregates [36]. GRSP has provided an important contribution to OC stability in soil aggregates or it has regulated it. The results showed that the contents of e-GRSP and t-GRSP exhibit significant positive correlation with the contents of OC and nitrogen in WSA with particle sizes $>2$ and $0.25-1 \mathrm{~mm}$. Moreover, e-GRSP and t-GRSP show significant negative correlation with WSA with particle sizes $<0.053 \mathrm{~mm}$ (Figure 2). Obviously, GRSP affects the stability of soil organic pool mainly through the regulation of organic matter in WSA with different particle sizes [16]; however, GRSP is focused on promoting the enrichment of organic matter in large WSA and inhibiting the accumulation of organic matter in the clay and silt to establish a rational agglomerate hierarchy and increase the retention time of exogenous organic matter in soil macroaggregates [37]. However, this finding requires that the organic matter in soil reaches certain threshold effectiveness.

\section{Conclusion}

We draw the following conclusion by studying the vertical distribution of soil GRSP in abandoned agricultural lands of different years in Minqin Oasis and the relationship between GRSP and WSA. (1) In general, the contents of e-GRSP and t-GRSP in abandoned agricultural lands are higher than those of traditional arable lands. Moreover, e-GRSP and t-GRSP contents increase as the years of land abandonment are extended. e-GRSP and t-GRSP exhibit a tendency of first increase and then decrease in the vertical section. The contents of e-GRSP and t-GRSP at a depth between 20 and $40 \mathrm{~cm}$ are higher than those of $0-20$ and $40-60 \mathrm{~cm}$. (2) e-GRSP and t-GRSP show significant or extremely significant positive correlation with WSA with particle sizes of $0.25-1,1-2$, and $>2 \mathrm{~mm}$. In addition, e-GRSP and t-GRSP have significant or extremely significant negative correlation with the clay and silt content $(<0.053 \mathrm{~mm})$. t-GRSP has extremely significant linear correlation with MWD $(P<0.01)$. (3) e-GRSP and t-GRSP have significant positive correlation with $\mathrm{OC}$ and $\mathrm{N}$ in WSA with particle sizes $>2$ and $0.25-1$ mm. e-GRSP and t-GRSP also exhibit significant negative correlation with OC content in clay and silt $(<0.053 \mathrm{~mm})$ $(P<0.05)$. Moreover, e-GRSP and t-GRSP show extremely significant negative correlation with $\mathrm{N}$ content in clay and silt $(<0.053 \mathrm{~mm})(P<0.05)$. e-GRSP and t-GRSP exhibit significant quadratic correlation with TOC content in soil in the study site $(P<0.05)$.

\section{Acknowledgements}

This research was supported by the National Natural Science Foundation of China (nos. 31560170, 41561062 and 41867013).

\section{References}

[1] Wright SF, Upadhyaya A, "A survey of soils for aggregate stability and glomalin, a glycoprotein produced by hyphae of arbuscular mycorrhizal fungi", Plant and Soil, vol. 198, pp. 97-107, 1998a.

[2] Huang Y, Wang DW, Cai JL, Zheng WS, "Review of glomalin-related soil protein and its environmental function in the rhizosphere", Chinese Journal of Plant Ecology, vol. 35, pp. 232-236, 2011.

[3] Rillig MC, Wright SF, Nichols KA, Schmidt WF, "Torn MS. Large contribution of arbuscular mycorrhizal fungi to soil carbon pools in tropical forest soils", Plant and Soil, vol. 233, pp. 167-177, 2001.

[4] Wu QS, He XH, Zou YN, He KP, Sun YH, Cao MQ, "Spatial distribution of glomalin-related soil protein and its relationships with root mycorrhization, soil aggregates, carbohydrates, activity of protease and $\beta$-glucosidase in the rhizosphere of Citrus unshiu", Soil Biology and Biochemistry, vol. 45, pp. 181-183, 2012.

[5] Pimentel D, Harvey C, Resosudarmo P, Kurz KSD, Crist MMS, Fitton LSL, Saffouri R, Blair R, "Environmental and economic costs of soil erosion and conservation benefits", Science, vol. 267, pp. 1117-1123, 1995.

[6] Ortas I, Akpinar C., Lal R, "Long-term impacts of organic and inorganic fertilizers on carbon sequestration in aggregates of an entisol in Mediterranean Turkey", Soil Science, vol. 178, pp. 12-23, 2013.

[7] Rillig MC, Maestre FT, Lamit LJ, "Microsite differences in fungal hyphal length, glomalin, and soil aggregate stability in semiarid Mediterranean steppes", Soil Biology and Biochemistry, vol. 35, pp. 1257-1260, 2003.

[8] Sun DF, Dawson R, Li BG. 2006. Agricultural causes of desertification risk in Minqin, China. Journal of Environmental Management 79: 348-356.

[9] Wang JQ, liu LC, Qiu XQ, Wei YJ, Li YR, Shi ZG, "Contents of soil organic carbon and nitrogen in water-stable aggregates in abandoned agricultural lands in an arid ecosystem of Northwest China”, Journal of Arid Land, vol. 8, pp. 350-363, 2016.

[10] Puget P, Chenu C, Balesdent J, "Dynamics of soil organic matter associated with particle-size fractions of water-stable aggregates", European Journal of Soil Science, vol. 51, pp. 595-605, 2000.

[11] Six J, Elliott ET, Paustian K, Doran JW, “Aggregation and soil organic matter accumulation in cultivated and native grassland soils", Soil Science Society of America Journal, vol. 62, pp. 1367-1377, 1998.

[12] Miwa A, Minamiya Y, Tsuzura H, Watanabe Y, Yagioka A, Kaneko N, "Changes in water stable aggregate and soil carbon accumulation in a no-tillage with weed mulch management site after conversion from conventional management practices", Geoderma, vol. 221-222, pp. 50-60, 2014.

[13] Manna M, Swarup A, Wanjari R, Mishra B, Shahi D, "Long-term fertilization, manure and liming effects on soil organic matter and crop yields", Soil and Tillage Research, vol. 94, pp. 397-409, 2007. 
[14] Spohn M, Giani L, "Impacts of land use change on soil aggregation and aggregate stabilizing compounds as dependent on time", Soil Biology and Biochemistry, vol. 43, pp. 1081-1088, 2011.

[15] Yamashita T, Flessa H, John B, Helfrich M, Ludwig B, "Organic matter in density fractions of water-stable aggregates in silty soils: Effect of land use", Soil Biology and Biochemistry, vol. 38, pp. 3222-3234, 2006.

[16] Wright SF, Upadhyaya A, "Extraction of an abundant and unusual protein from soil and comparison with hyphal protein of arbuscular mycorrhizal fungi”, Soil Science, vol. 161, pp. 575-586, 1996c.

[17] Xie XL, Xu PY, Zhu HH, Yao Q, "Extraction conditions of glomalin-related soil protein", Mycosystema, vol. 31, pp. 92-99 (in Chinese with English abstract), 2011.

[18] Bremner J M. Nitrogen-total. In: Sparks D L, "Methods of Soil Analysis. Part 3. Chemical Methods", Madison, WI: Soil Science Society of America, pp. 1085-1121, 1996.

[19] Institute of Soil Science, "Chinese Academy of Sciences. Soils in China", Beijing: Science Press, (in Chinese), 1978.

[20] DuPont ST, Culman SW, Ferris H, Buckley DH, Glover JD, "No-tillage conversion of harvested perennial grassland to annual cropland reduces root biomass, decreases active carbon stocks, and impacts soil biota", Agriculture, Ecosystems and Environment, vol. 137, pp. 25-32, 2010.

[21] Rillig MC, Wright SF, Allen MF, Field CB, "Rise in carbon dioxide changes soil structure", Nature, no. 400, vol. 6745, pp. 628-628, 1999.

[22] Wright SF, Franke-Snyder M, Morton JB, Upadhyaya A, "Time-course study and partial characterization of a protein on hyphae of arbuscular mycorrhizal fungi during active colonization of roots", Plant and Soil, vol. 181, pp. 193-203, 1996 b.

[23] Wang CY, Feng HY, Yang ZF, Xia XQ, Tao YU. "Glomalin-related soil protein distribution and its environmental affecting factors in the northeast inner mongolia”, Arid Zone Research, vol. 30, pp. 22-28, 2013.

[24] Talbot JM, Allison SD, Treseder KK, "Decomposers in disguise: mycorrhizal fungi as regulators of soil $\mathrm{c}$ dynamics in ecosystems under global change", Functional Ecology, pp. 22, vol. 955-963, 2008.

[25] Zhong ZL, Wang WJ, Wang Q, Ren J, "Correlation between soil physicochemical properties and fungi-derived glomalin-related soil proteins in agricultural region of Songnen Plain", Chinese Journal of Ecology, vol. 34, pp. 2274-2280, 2015.
[26] Staddon PL, Ramsey CB, Ostle N, Ineson P, Fitter AH, "Rapid turnover of hyphae of mycorrhizal fungi determined by AMS microanalysis of ${ }^{14}$ C", Science, vol. 300, pp. 1138-1140, 2003.

[27] He XL, Chen C., He B, "Spatial distribution of arbuscular mycorrhizal fungi and glomalin of Hippophae rhamnoides $\mathrm{L}$ in farming-pastoral zone from the two northern provinces of China”, Acta Ecologica Sinica, vol. 31, pp. 1653-1661, 2011.

[28] Wright SF, Upadhyaya A, "Extraction of an abundant and unusual protein from soil and comparison with hyphal protein of arbuscular mycorrhizal fungi”, Soil Science, vol. 161, pp. 575-586, 1996a.

[29] Cheng L, Booker FL, Tu C, Burkey KO, Zhou L, Shew HD, Rufty TW, Hu S, "Arbuscular mycorrhizal fungi increase organic carbon decomposition under elevated $\mathrm{CO}_{2}$ ", Science, vol. 337, pp. 1084-1087, 2012.

[30] Rillig MC, Wright SF, Shaw MR, Field CB, “Artificial climate warming positively affects arbuscular mycorrhizae but decreases soil aggregate water stability in an annual grassland", Oikos, vol. 97, pp. 52-58, 2002.

[31] Liu XW, He XL, "The spatio-temporal distribution of arbuscular mycorrhizal fungi of Oxytropis aciphylla rhizosphere in the area of Shapotou", Journal of Agricultural University of Hebei, vol. 31, pp. 52-56+65, 2008.

[32] Rillig MC, "Arbuscular mycorrhizae, glomalin, and soil aggregation”, Canadian Journal of Soil Science, vol. 84, pp. 355-363.

[33] Beare MH, Hendrix PF, Coleman DC, "Water-stable aggregates and organic matter fractions in conventional and no-Tillage soils", Soil Science Society of America Journal, vol. 58, pp. 777-786, 1994.

[34] Feng G, Zhang YF, Li XL, "Effect of external hyphae of arbuscular mycorrhizal plant on water -stable aggregates in sandy soil", Journal of Soil and Water Conservation, vol. 15, pp. 99-102, 2001.

[35] Simansky V, Bajcan D, "Stability of soil aggregates and their ability of carbon sequestration", Soil and Water Research, vol. 9, pp. 111-118, 2014.

[36] Zhu YG, Miller RM, "Carbon cycling by arbuscular mycorrhizal fungi in soil-plant systems", Trends in Plant Science, vol. 8, pp. 407-409, 2003.

[37] Oades JM, Waters AG, "Aggregate hierarchy in soils", Australian Journal of Soil Research, vol. 29, pp. 815-828, 1991. 